phrenia had the following blood picture: Hb $150 \%$ (cyanmethaemoglobin method); P.C.V. $70 \%$; W.B.C. $16,800 / \mathrm{mm}^{3}$ (neutrophils $90 \%$ ); platelets $450,000 / \mathrm{mm}^{3}$. There was a good response to venesection and 32P. In March 1972, when severely paranoid, he became unsteady on his feet. Examination of the central nervous system was normal: the $\mathrm{Hb}$ was $121 \%$; P.V.C. $68 \%$; platelets $267,000 / \mathrm{mm}^{3}$; leucocyte alkaline phosphatase score 115 per 100 neutrophils (normal 30-100). Soon after venesection numbness developed down the left side: it improved in a few days. Exaggerated left lower limb reflexes and an equivocal left plantar response were later apparent. By June the left lower limb was spastic with ankle clonus and an extensor plantar response, the left arm was weak, and there was urinary incontinence. A cerebral tumour was thought possibly to be causing a progressive hemiplegia. Chest and skull radiographs and a brain scan were normal. After increasing loss of consciousness he died in July.

Postmortem examination showed no evidence of neoplastic disease nor any endocrine, respiratory, cardiovascular, or renal abnormality associated with a secondary polycythaemia. The spleen weighed $270 \mathrm{~g}$ and histological examination showed only venous congestion. The bone marrow was hyperplastic and all elements were increased in relatively normal proportions. The brain was generally oedematous with recent thrombotic occlusion of the superior cerebral veins on both sides and a patent superior sagittal sinus. Cut sections showed petechial haemorrhages within the white matter of the right and left frontal and parietal lobes. Histologically the appearances were of early venous occlusion. At the right frontal and left occipital poles were old infarcts with cyst formation typical of lesions from arterial occlusion. There was less cerebral arteriosclerosis than might have been expected in a man of his age.

We emphasize again that the clinical picture as it progressed over several months resembled a slowly-growing cerebral tumour. We wish to thank Dr. J. E. Ffoulkes-Edwards for permission to report this case.-We are, etc.,

D. G. Sims

Basingstoke District Hospital,

E. M. Husband

Basingstoke, Hants

\section{Malignant Lymphoma and Acute S.L.E.}

SIR,-The interesting report by Drs. A. G. Cudworth and A. Ellis (29 July, p. 291) of a case of malignant lymphoma and acute systemic lupus erythematosus prompts me to record that I have seen two cases of Hodgkin's disease with clearly defined lupus erythematosus syndromes-one in a man aged 24 and the other in a man aged 41 . We have also seen a number of other malignant reticuloses which were preceded by various conditions of an allergic or autoimmune nature, including arteritis. ${ }^{1}$ In most cases the connective tissue disorder of essentially non-malignant character has preceded the irreversible, or malignant, lymphoma, but nearly all our cases of reticuloses, including chronic lymphocytic leukaemia, lymphosarcoma, and reticulosarcoma, and the paraproteinaemias, have had histories of recurrent or chronic inflammatory conditions of various origin ${ }^{2}$ acting as a stimulus to the reticuloendothelial system. In addition, high antibody titres against toxoplasma were found in approximately $90 \%$ of these patients (compared with an incidence of $56 \%$ at the most in controls matched for $\mathrm{age}^{34}$ ).

Such a stimulus, be it chemical, viral, bacterial, protozoal, or allergic, will lead to a reactive proliferation of the target tissue, with or without the production of antibodies. The number of mitoses in a proliferating tissue is increased and with it the number of spontaneous mutations will rise. Mutations may also be promoted by some of the drugs given or even by the stimulating agent itself. Though the majority of mutants have no chance of survival, with an increased total number the number of survivors will also increase. Some of these mutants will multiply and grow to become an abnormal cell clone.-I am, etc.,

\section{ROSE SCHEUER-KARPIN}

Department of Haemato'ogy,
Kingston General Hospital,

1 Scheuer-Karpin, Rose, and d'Heureuse-Gerhardt, R., Proceedings of the Third Congress of the Asian and Pacific Society of Haematology, Scheuer-Karpin, Rose, Proceedings of the Seventh Congress of the European Society of Haemat
1960.

1960.
Scheuer-Karpin, Rose, Thesis, Humboldt Univer-

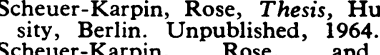
Rose, and d'Heureuse22, 1393 .

\section{Lumbar Disc Problems}

SIR,-I am surprised that one of the calibre of Mr. A. H. G. Murley should expect us to accept his beliefs (26 August, p. 529) in this scientific age when nothing is acceptable unless it can be reasonably proved by adequate demonstration or experiment. In the case of disc lesions this has long since and very adequately been done by James Cyriax ${ }^{1}$ and also by many others who have contributed adequate evidence to show that disc lesions are indeed commonplace rather than rarities.

Whether damage to the posterior joints predisposes to disc prolapse is anothe question. Cyriax has proved that these joints are rarely capable of being the cause of the pain. It is a great misfortune that people I have come across who have had their backache cured after more than 20 years either by manipulation or traction should have had to suffer so long without effective treatment simply because they had been told that they were suffering from chronic muscle or join sprains. Finally, I am astonished to see $\mathrm{Mr}$. Murley confess that he manipulates sprains. I will certainly avoid him when I sprain my ankle, but when my knee locks owing to my torn cartilage I should be delighted to visi him for manipulation, which is the appropriate treatment for an internal derangement of a joint, be it meniscus or disc.-I am, etc.,

\section{Sheerness, Kent}

\section{R. T. D. FitzGERALD}

Cyriax, J., Textbook of Orthopaedic Medicine, 5th
edn. London, Bailliere, Tindall and Cassell edn.

\section{Undergraduate Curriculum}

SIR,-The symposium on the undergraduate curriculum as a preparation for general practice at the B.M.A.'s Annual Meeting (5 August, p. 339) was disappointing, its title unfortunate. I hope medical schools, old and new, will not alter their curricula to be preparations for a particular discipline but continue to concentrate on the undergraduate's education, especially as he has spent his years in the sixth form specializing in two or three relatively narrow subjects. If we take education to be the means by which new knowledge is discovered and new interpretations put on established ideas, and it must produce the urge to question presuppositions, then I fully support the introduction of the undergraduate to the discipline of general practice. The student will have the opportunity of gaining a further understanding of human behaviour and to observe the many variations by the patient in the presentation of his fears at the time of first contact (from the request for a tonic to the self-diagnosis). Such experience must surely benefit the student whatever his future. It is neither appropriate nor advisable to consider this as a preparation for future general practitioners, any more than his study of pathology as a preparation for future pathologists.

Underground education completed, his continuing education will be modified to include an element of training. At some stage he will opt for the discipline of general practice. His training now will need the same guidance and intensity as for other disciplines.

New departments of general practice are springing up in our medical schools and pressures are exerted in those schools, at present without a chair, to keep abreast of the times and up with the Joneses. I agree with Professor P. B. Beeson that their concern with undergraduate education, though important, will be small. Postgraduate training will be a formidable challenge in the coming years. No mention has been made of the need for research in general practice, what we are trying to do, how best to achieve it, and the better use of present and future facilities.

I have no doubt of the need for such departments in our medical schools. The understanding of their function is obviously urgent.-I am, etc.,

Liverpool

G. E. Crawford

1 James of Rusholme, Lord, Proceedings of Royal Society of Medicine, 1971, 64, 441.

\section{Dysphagia and Sarcoid Granulomas}

SIR,-In the unusual patient described by Dr. R. J. Davies (2 September, p. 564), who had had sarcoidosis for 14 years, the Tensilon test was negative but the muscle atrophy around the lesions in the oesophagus was reminiscent of that seen in myasthenia gravis.

Four reported cases of myasthenia had sarcoidosis, ${ }^{1}$ and at least $\mathbf{3 0}$ more had giantcell myocarditis, which possibly may arise from subclinical sarcoidosis. ${ }^{2}$ Myocardial sarcoidosis is more common than was realized, ${ }^{3}$ particularly as the infiltration in the late stages cannot be identified with any certainty. Possibly idiopathic cases of cardiomyopathy may begin as sarcoidosis. Probably autoimmunity is a factor in this type of heart disease 4 as well as in generalized sarcoidosis. ${ }^{5}$ Eosinophilia is sometimes seen in the later condition ${ }^{6}$ and random eosinophile counts of $7 \%, 8 \%$, and $10 \%$ were found in three of my five patients with unexplained cardiomyopathies. Even when no initial symptoms or signs occur the longterm effects of sarcoidosis can be severe. Much time has been spent defining the 